\title{
Longitudinal Evaluation of Oral Health Among Orthodontic Patients Prior Treatment, During Treatment and Post-Treatment
}

\author{
Hisham M. Abozaid ${ }^{* 1}$, Laila AF Amer ${ }^{2}$
}

Codex : 08/2021/10

Aadj@azhar.edu.eg

\section{KEYWORDS}

Gingival bleeding index, orthodontic patients, oral hygiene, gingivitis, plaque index

1. Department of Oral Medicine, Periodontology, Diagnosis \& Oral Radiology, Faculty of Dental Medicine, (Cairo, boys), Al-Azhar University, Egypt.

2. Department of Orthodontics, Faculty of Oral and Dental Medicine, MTI University, Cairo, Egypt.

* Corresponding Author e-mail: hishamabouzaid.209@azhar.edu.eg

\begin{abstract}
Aim: to evaluate oral health status among orthodontic patients: before, during, post treatment completion. Subjects \& methods: Twenty-eight patients were selected from Outpatient clinics seeking Orthodontic treatment, Faculty of Dental Medicine, Al-Azhar University, Cairo, Egypt. A self-administrated questionnaire was prepared covering oral hygiene practice, oral hygiene cleaning aids and previous oral prophylaxis. Oral health status of each patient was assessed using: Gingival bleeding index (GBI), Plaque index (PI), Oral Hygiene Index (OHI-S) which performed for each patient 3; prior to, during and after orthodontic treatment termination. Measurement of probing pocket depth (PPD) and radiographic examination were done before treatment and 3 months following treatment termination. Results: No significant difference was observed between mean PI \& GBI recorded before orthodontic treatment(T1) and that measured three months (T4) following treatment completion but there were significant differences between these measurements during treatment with both before and after treatment; no significant difference between males and females. PPD recorded no differences between any evaluation times. OHI-S recorded higher scores during treatment period with statistically significant difference when compared with recorded scores initially; however, it did not differ significantly with that of at after 3 from orthodontic termination. Conclusion: Dental plaque accumulation among orthodontic patients can aid in development of gingival and dental effects, as it seems likely that orthodontic appliances have potentiality to increase oral microbial population. Orthodontic patients should be monitored and motivated for proper oral hygiene to avoid risk of new caries and periodontal diseases.
\end{abstract}

\section{INTRODUCTION}

The presence and maintaining a good oral hygiene is prerequisite to ensure successful orthodontic treatment and the assessment of oral hygiene practices is essential for adequate understanding of patients' oral healthcare needs. ${ }^{1}$ However, it was difficult to implement a comprehensive oral hygiene regimen in orthodontic patients; as more dental plaque can be build-up with greater rate in patients wearing 
fixed orthodontic appliances due to difficulty of teeth cleaning. ${ }^{2,3}$ Worsening of clinical parameters of periodontal diseases, as plaque index, bleeding on probing, attachment loss, and onset of pockets or gingival recessions, in association with time and type of orthodontic treatment has been reported in systematic reviews. ${ }^{4}$ Reasons for periodontal diseases onset among orthodontic patients may be attributed to: more difficult maintenance of oral hygiene, plaque retention to orthodontic devices, bone/periodontal movements and remodeling under orthodontic forces, which favor subgingival plaque accumulation and enhance periodontal pathogenic potential.5, ${ }^{6}$ Even with good cleaning of teeth during orthodontic treatment period, generalized gingivitis commonly developed in most patients.? Dental plaque accumulation / retention may cause subsequent oral health problems including decalcification, dental caries, periodontal disease, halitosis and teeth staining. ${ }^{8}$ The oral microbiota is the collection of more than 600 microbial species eukaryotes, archaea, bacteria, fungi, and viruses living in specific ecological niches of oral cavity ${ }^{9}$, 169 of which constitute the indigenous "core oral microbiome", whose species are qualitatively and quantitatively housed in three different niches, classified as: Group 1, buccal mucosa, keratinized gingiva, hard palate; Group 2, saliva, tongue, tonsils, and throat (back wall of oropharynx); and Group 3, sub- and supra-gingival plaque. ${ }^{10}$ Patients and dental professionals should participate actively in controlling plaque build-up process through maintaining good oral hygiene condition.

Clinical and microbial differences existed in plaque samples from orthodontic patients and subjects not undergoing orthodontic treatment; as there was shift toward predominance of some bacterial species, known to be periodontal pathogens. Orthodontic subjects showed highest increase 3 months following orthodontic appliances placement and significant association of strongly pathogenic P. gingivalis bacterial species with gingivitis. ${ }^{11}$ Amounts of red-complex bacteria (P. gingivalis, $\mathrm{P}$. intermedia and T. forsythia and A. actinomycetemcomitans) were considered in meta-analysis study; only $\mathrm{T}$. forsythia showed a statistically significant increase 3 months after orthodontic appliances, while a transient increase of all other considered species was noted 6 months after treatment initiation. P. intermedia species were more significantly increased at incisors area than at molars area. Additionally, elevated levels of P. gingivalis, P. intermedia / P. nigrescens, T. forsythia, and Fusobacterium spp., were found in orthodontic patients 3 months after brackets placement compared to control group and baseline. Gram-negative superinfecting bacteria and enteric rods were found indistinctly in all groups, without significant differences. ${ }^{12} \mathrm{~A}$ decrease in Actinomyces spp. after 1 year of treatment was also reported in samples from 17 adults with full-fixed orthodontic appliances ${ }^{13}$; during treatment, P. intermedia and other orange complex species increased, while red complex species proportion remained unchanged; return to pretreatments levels several months after removal of fixed appliances was reported. Similarly, microbial changes occurring in subgingival plaque samples from 30 orthodontic patients 3 months after removal of fixed orthodontic appliances compared to healthy subjects not undergoing orthodontic treatment. ${ }^{14}$

Lo et al. ${ }^{15}$ reported prevalent aerobic flora before orthodontic treatment and one year from treatment initiation, with prevalent of facultative aerobic and anaerobic species during the first 2-4 weeks of treatment. Mean counts of $\mathrm{P}$. gingivalis were similar on metallic and ceramic brackets isolated from both posterior and anterior teeth. ${ }^{16}$ The two types of bracket exhibited statistical differences in counts of 8 periodontal pathogen species: metallic bracket showed significant increased levels of $\mathrm{T}$. denticola, A. actinomycetemcomitans, F. nucleatum, S. anginosus and E. nodatum, while in ceramic ones E. corrodens, Capnocytophaga, Selenomonas noxia were most increased species. ${ }^{17}$ 
The consistent quantitative and qualitative changes in the plaque one month after the start of orthodontic treatment were confirmed by a systematic review; ${ }^{12}$ different orthodontic appliances tended indiscriminately to alter the oral microbiota during treatment, but fixed appliances reported a greater and significant cariogenic and periodontal pathogen effect than removable appliances. In this situation, Müller et al., concluded that reversibility of periodontal changes and permanence of enamel demineralization and white spots suggesting the use of antibacterial orthodontic bonding systems as an adjunct in maintenance of proper dental health in orthodontic patients. ${ }^{18}$ A study indicated that, 6 months after insertion of fixed/removable orthodontic appliance, microscopic counts of oral bacteria were increased; patients with fixed orthodontic appliances have an increased risk of white-spot lesion formation due to the oral microbiota changes, in particular $S$ mutans which has a key role in dental caries formation..$^{19}$ Orthodontic treatments may affect the oral microbiota equilibrium, as bands, brackets, wires and acrylic resins increase the risk of retention of food particles and microorganisms. Significant increase in PI and GI, no changes in PPD after the first 3 months of therapy and a decrease in PI, GI, and PPD 6 months after appliance removal was reported and at end of orthodontic therapy, periodontal parameters were higher than those at baseline; indicating that fixed orthodontic appliance promotes dental plaque accumulation and gingival inflammation; but orthodontic appliances seemed to have no permanent effects on periodontal status. ${ }^{20}$ Clinical and microbiological changes after removal of fixed appliances was reported; PPD and BOP were assessed at baseline (T1), appliance removal (T2) and 3 months post-treatment (T3). Clinical parameters showed a significant increase between $\mathrm{T} 1$ and T2and a decrease between T2 and T3. They concluded that fixed appliances have an impact on microbial and clinical parameters; the periodontal values tended to normalize after de-bonding, but most values remained elevated after de-bonding compared with baseline. ${ }^{21}$ A study showed increased periodontal parameters from baseline to bracket removal and decreased 2 years after treatment; a normalization of clinical parameters, but some periodontal indexes were only partially reversed..$^{22,23}$

For the best of our knowledge, performing a longitudinal research on the oral health condition among orthodontic patient comparing that assessed prior to treatment initiation, during orthodontic treatment as well as after treatment termination, received little attention. Thus, the present study was designed and performed in an attempt to clarify this aspect.

\section{PATIENTS AND METHODS}

\section{Study Group}

Included patients who needed orthodontic treatment were free of systemic disease and had not used antibiotics and/or steroids in the last 3 months. They were asked to inform us if they had used any kind of medication or antibacterial agents two weeks before bacterial sample collection; any use of medications was reported and patients were excluded. They were examined intraorally and radiologically with regard to indication of orthodontic treatment and subsequently. Before orthodontic treatment starting, each patient received oral prophylaxis as well as hygiene instructions included the correct use of a toothbrush. Oral hygiene of each one of them was considered to be ideal at the beginning of the orthodontic treatment.

Twenty eight patients who attended postgraduate orthodontic clinic at Faculty of Dental Medicine, Al-Azhar University, Cairo, were included into the present study. They were seeking and indicated to have orthodontic treatment with fixed appliances; study protocol was approved by the Faculty Ethics Committee. A self-administered questionnaire was distributed and participants were requested to sign consent form and answering questionnaire contains two parts: a) Socio-demographic characteristics, b) Oral hygiene $(\mathrm{OH})$ practices. Socio-demographic 
variables included age, gender, race, level of education, and smoking status. $\mathrm{OH}$ practices were assessed through questions on type, and frequency use of toothbrush, other cleaning materials or tools used daily such as dental floss, mouth rinse, interdental brush, and toothpick and dental scaling visits during their orthodontic treatment period.

\section{Orthodontic Treatment:}

Following the obtaining of the answered questionnaire and completion of complete clinical examination, each patient was appointed to start the planned orthodontic treatment according to his / her situation. However, all of them were treated with fixed orthodontic appliances. Each patient was scheduled of follow up to continue orthodontic treatment steps.

\section{Oral Health Assessment}

The health status of periodontal tissues was determined using: a) modified plaque index (PI) according to Silness and Loe. ${ }^{24}$ The PI was assessed according to plaque accumulation in the gingival area in four grades with the following scoring criteria: 0 , no plaque or debris on inspection and probing; 1 , a thin film of plaque only visible after probing; 2, a ribbon-like layer of plaque covering the sulcus and gingival crown areas but not filling the interdental spaces; and 3, a thick layer of plaque visible on inspection and filling the interdental spaces. b) Gingival bleeding index of Loe \&
Silness $\left.;{ }^{25} \mathbf{c}\right)$ Simplified Oral hygiene index of Greene $\&$ Vermillion; ${ }^{26}$ which has two components (Debris index \& Calculus index). d) Probing pocket depth (PPD) was done using graduated periodontal probe. They were recorded at 4 appointments: immediately prior to placement of orthodontic appliances (T1), 3 month \& 9 month following orthodontic treatment initiation (T2), and at 3 month after orthodontic treatment termination (T3). After each appointment, proper oral hygiene instructions were given to the all patients and to brush their teeth with fluoride containing toothpaste* two times / day for a minimum of 3 minutes each time.

Dental caries was diagnosed applying the $\mathrm{WHO}$ diagnostic criteria for epidemiological studies; 27 teeth were marked as 'decayed' when any of following was noted: unmistakable cavitation on occlusal, buccal, or lingual walls of the tooth; a detectable softened floor or wall, or remaining, carious roots; and a filled tooth with signs of caries. Caries occurrence was expressed as decayed, missing (due to caries), and filled permanent teeth (DMFT) count.

\section{Radiographic Evaluation}

Radiographs (periapical and panoramic views) were performed before treatment and 3 months after treatment completion. They were used to evaluate the caries status and teeth supporting structures that helped in detection of early changes involving hard structures (Fig. 1).
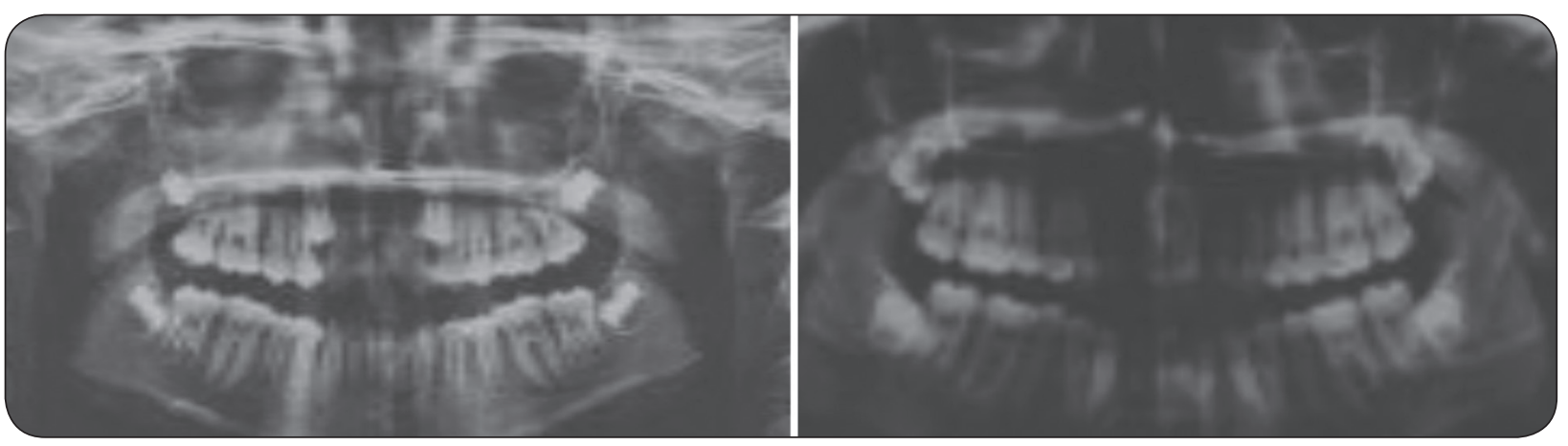

Fig. (1) Panoramic radiographs of two patients; they were treated with orthodontically. 


\section{Statistical Analysis}

This was carried out by Wilcoxon and Manne Whitney U tests; descriptive data were given as appropriate as calculated using SPSS version 15 (SPSS, Chicago, IL, USA). Differences were considered statistically significant when $P$ value $\leq$ 0.05 . Reliability was tested as $10 \%$ of randomly selected radiographs were re-examined for second time two weeks after the first examination by same examiner, and a reproducibility of $100 \%$ was obtained in identifying changes affecting hard teeth and periodontium.

\section{RESULTS}

\section{A. Bio demographic Findings:}

Twenty-eight orthodontic patients were included; all of them completed the study and comply with the protocol planned. More than half of them were students ( $\mathrm{n}=16 ; 57.1 \%), 7$ were working $(25 \%), \& 5$ without work $(17.9 \%)$. Majority were non-smokers $(\mathrm{n}=24 ; 85.7 \%)$. Most patients were performing the tooth-brushing once a day $(60.7 \%)$, while the rest
(39.3\%) used to brush their teeth twice a day. Twenty patients $(71.4 \%)$ preferred to use soft toothbrush, and eight patients were using medium tooth brushes $(28.6 \%)$. Daily use of other oral hygiene measures were: 15 patients $(53.8 \%)$ used interdental brush, 13 patients (46.4\%) used mouthwash, while dental floss silk was used by 8 patients $(28.6 \%)$ and toothpick use by only 6 patients $(21.4 \%)$. These data are illustrated in Fig. 2

\section{B. Results of Clinical Parameters Measurements:}

The plaque index (PI) recorded high mean scores $(1.56 \pm$ SD 0.38 and $1.72 \pm$ SD 0.34$)$ at $3 \& 9$ months of orthodontic treatment (T2 \&T3), respectively. No significant difference was observed between mean PI recorded before orthodontic treatment(T1) and that measured three months (T4) following treatment completion $(p=0.845)$, but a significant difference was observed when comparing between measurements during treatment with both before and after treatment ( $\mathrm{p} \leq 0.05)$; (Table 1). Fig. 3 presenting the clinical appearance of gingiva of two patients before treatment and 3 months after orthodontic treatment termination.

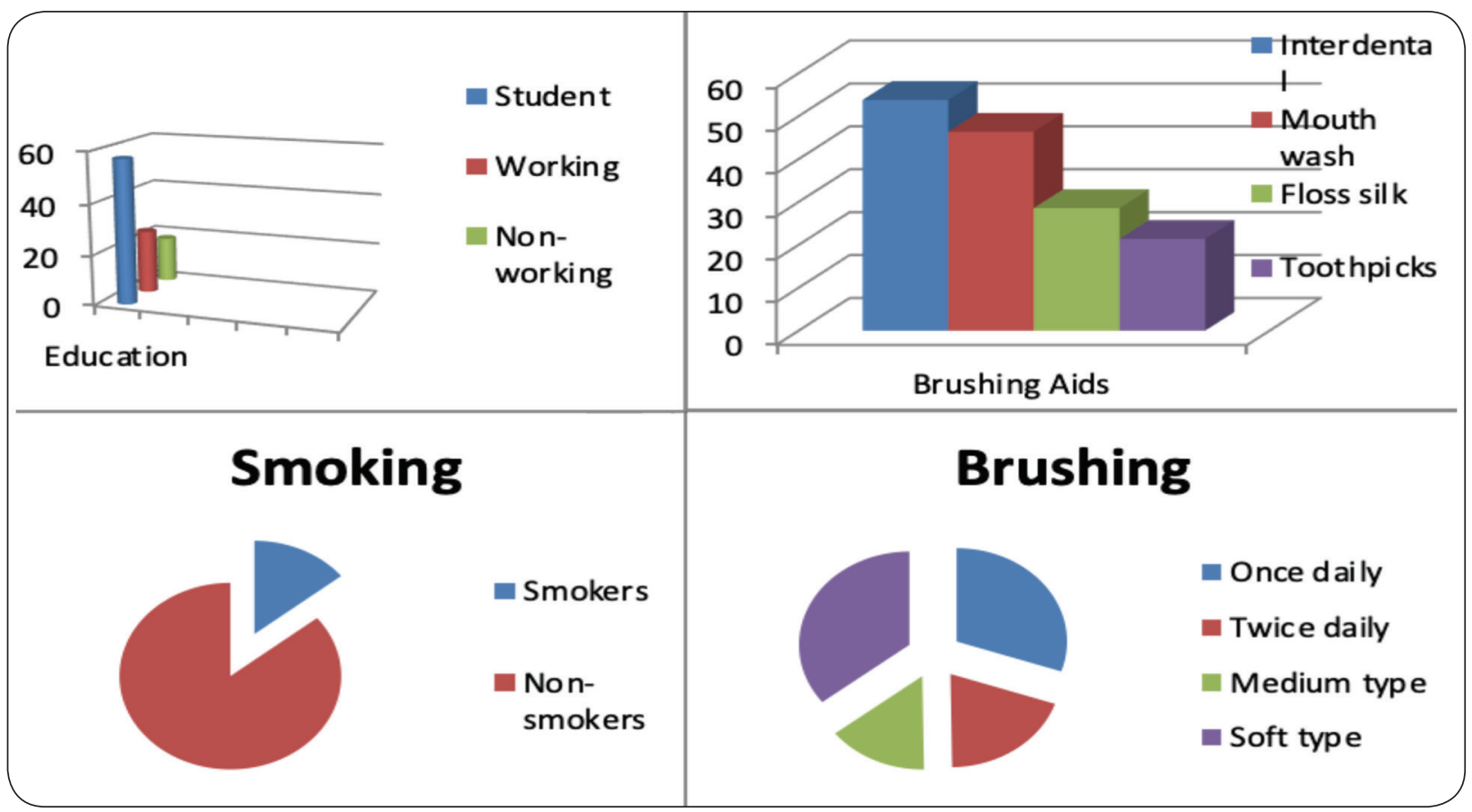

Fig. (2) Presenting the education state, tooth brushing use \& type and use of other cleaning aids among the included sample of orthodontic; these variables are presented as \%. 


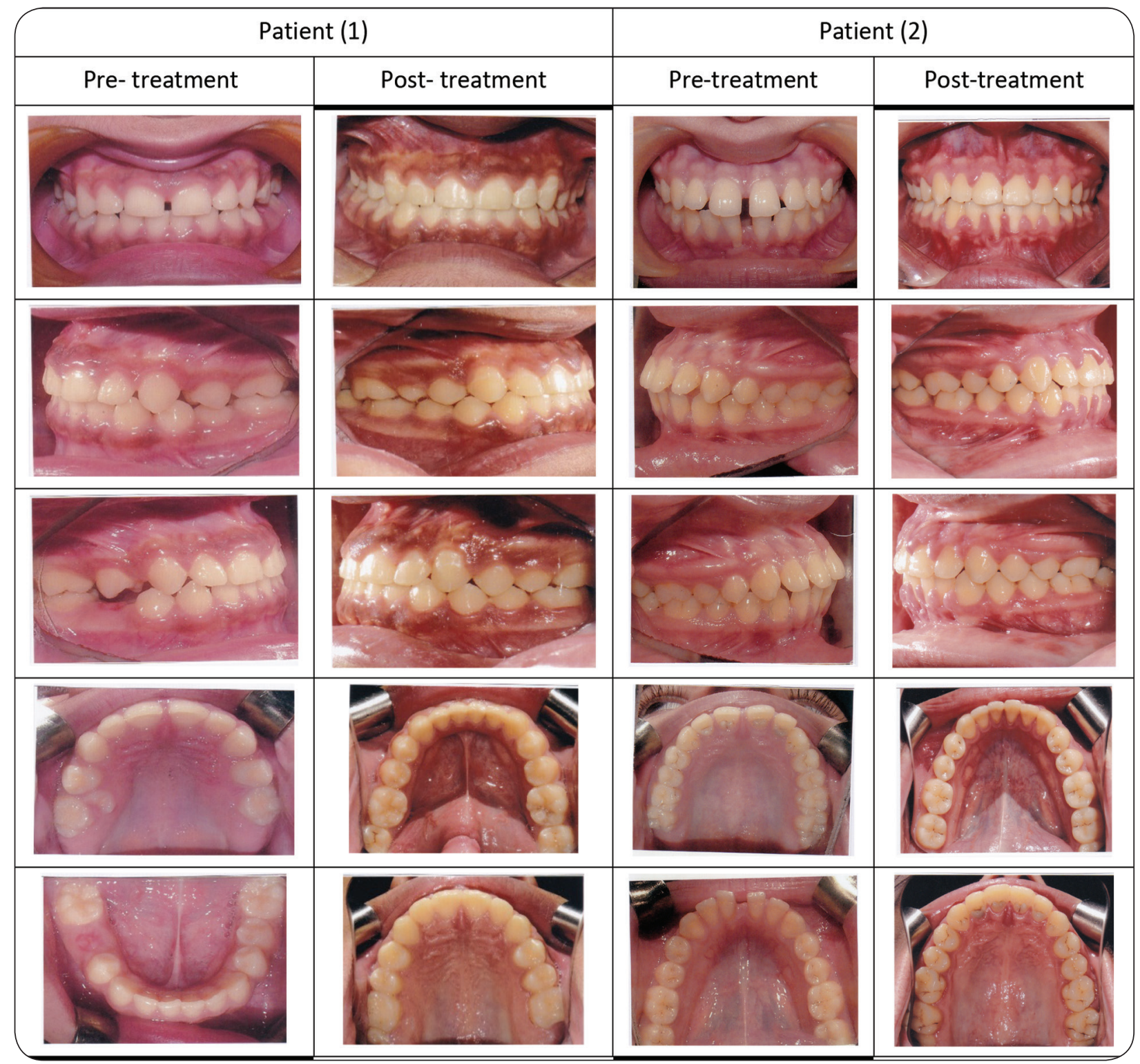

Fig. (3) Clinical presentation of two patients before and after orthodontic treatment

The OHI-S showed the included patients had fair oral hygiene at the time of starting orthodontic treatment. This index recorded higher scores during treatment period with statistically significant difference when compared with recorded scores initially $(\mathrm{p} \leq 0.05)$, however it did not differ significantly with that recorded after 3 from orthodontic termination ( $\mathrm{p} .>0.05)$. Table 2

The GBI showed highest mean score during treatment (T2 and T3) compared with those recorded before treatment (T1) and after treatment termi- nation (T4); difference was statistically significant $(p \leq 0.05)$. Again the recorded measurements of GBI mean scores did not differ significantly between that recorded before treatment with after treatment ( $>00.05$ ); Table 3. Probing pocket depth (PPD) showed that all included patients had normal depth of gingival crevice; there were no actual loss of attachment. Some patient recorded increased depth of sulcus during treatment period due to inflammatory changes involving gingival tissue. However, such change was transient as with resolution of inflammation, there was no existence of this finding. 
Table (1) Changes of Plaque Index (PI) recorded from orthodontic patients before (T1), during (T2, T3) and after treatment (T4) with fixed appliances.

\begin{tabular}{|c|c|c|c|c|c|}
\hline \multirow{2}{*}{$\begin{array}{c}\text { Time of } \\
\text { examination }\end{array}$} & \multicolumn{2}{|c|}{ Range } & \multirow{2}{*}{ Mean } & SD & p value \\
\cline { 2 - 3 } & Minimum & Maximum & & & T1/T2, T1/T3* \\
\hline $\mathrm{T} 1$ & 0.08 & 0.45 & 0.26 & 0.19 & $\mathrm{~T} 2 / \mathrm{T} 3, \mathrm{~T} 3 / \mathrm{T} 4 *$ \\
\hline $\mathrm{T} 2$ & 1.30 & 2.0 & 1.56 & 0.38 & $\mathrm{~T} 3 / \mathrm{T} 4 * *$ \\
\hline $\mathrm{T} 3$ & 1.64 & 2.34 & 1.72 & 0.34 & 0.32 \\
\hline $\mathrm{T} 4$ & 0.40 & 1.10 & 0.48 & & \\
\hline
\end{tabular}

Table (2) Changes of Oral Hygiene Index (OHI) recorded from orthodontic patients before (T1), during (T2, T3) and after treatment (T4) with fixed appliances.

\begin{tabular}{|c|c|c|c|c|c|}
\hline \multirow{2}{*}{$\begin{array}{c}\text { Time of } \\
\text { examination }\end{array}$} & \multicolumn{2}{|c|}{ Range } & \multirow{2}{*}{ Mean } & \multirow{2}{*}{$S D$} & \multirow{2}{*}{$p$ value } \\
\hline & Minimum & Maximum & & & \\
\hline $\mathrm{T} 1$ & 0.25 & 0.60 & 0.42 & 0.15 & $\mathrm{~T} 1 / \mathrm{T} 2, \mathrm{~T} 1 / \mathrm{T} 3 *$ \\
\hline $\mathrm{T} 2$ & 2.10 & 2.80 & 2.40 & 0.25 & $\mathrm{~T} 2 / \mathrm{T} 3, \mathrm{~T} 3 / \mathrm{T} 4 *$ \\
\hline $\mathrm{T} 3$ & 2.35 & 3.10 & 2.62 & 0.40 & $\mathrm{~T} 3 / \mathrm{T} 4 * *$ \\
\hline $\mathrm{T} 4$ & 0.60 & 1.60 & 0.75 & 0.55 & \\
\hline
\end{tabular}

Table (3) Changes of Gingival bleeding Index (GBI) recorded from orthodontic patients before (T1), during $(T 2, T 3)$ and after treatment (T4) with fixed appliances.

\begin{tabular}{|c|c|c|c|c|c|}
\hline \multirow{2}{*}{$\begin{array}{c}\text { Time of } \\
\text { examination }\end{array}$} & \multicolumn{2}{|c|}{ Range } & \multirow{2}{*}{ Mean } & SD & $p$ value \\
\cline { 2 - 3 } & Minimum & Maximum & & 0.07 & $\mathrm{~T} 1 / \mathrm{T} 2, \mathrm{~T} 1 / \mathrm{T} 3 *$ \\
\hline $\mathrm{T} 1$ & 0.00 & 0.20 & 0.12 & 0.24 & $\mathrm{~T} 2 / \mathrm{T} 3, \mathrm{~T} 3 / \mathrm{T} 4 *$ \\
\hline $\mathrm{T} 2$ & 1.20 & 1.60 & 1.35 & 0.18 & $\mathrm{~T} 3 / \mathrm{T} 4 * *$ \\
\hline $\mathrm{T} 3$ & 1.48 & 1.80 & 1.52 & 0.24 & \\
\hline $\mathrm{T} 4$ & 0.25 & 0.85 & 0.35 & & \\
\hline
\end{tabular}

$* P \leq 0.05, \quad * * P>0.05$

These findings regarding the measurements of various clinical parameters assessed the periodontal health status were illustrated in Fig.4.

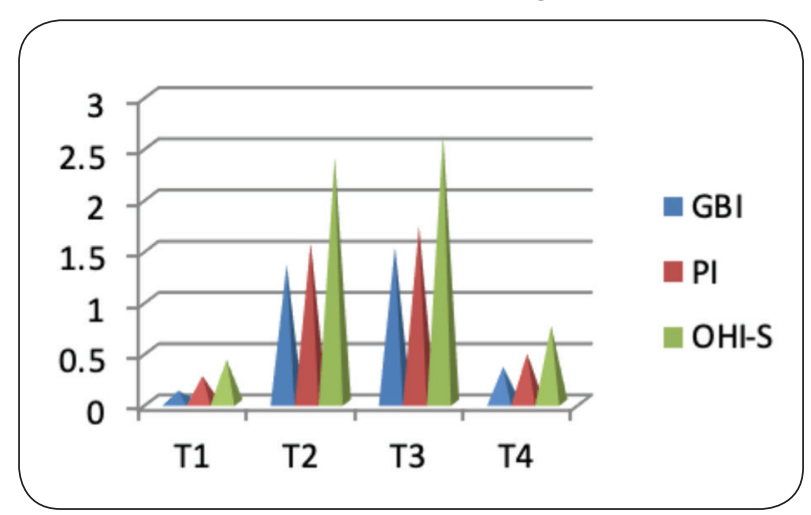

Fig. (4) Clinical parameters recorded before orthodontic treatment (T1), during treatment (T2 and $\mathrm{T} 3$; at $3^{\text {rd }}$ and $9^{\text {th }}$ months, respectively and 3 months post-treatment (T4).

\section{Findings of Teeth condition (DMFT)}

The presence of missing / decayed / filled teeth were checked and counted in all included patients before treatment starting and 3 months following treatment completion. For clarity and simplicity, the findings were presented in 4 divisions: upper anterior teeth, upper posterior teeth, lower anterior teeth and lower posterior teeth. Before starting of orthodontic treatment, missing teeth were 16 in 4 patients (premolars), filled teeth were 16 in 4 patients, also, (all were molars on both arches), 
while no decayed were present. After treatment completion, there was no change in number of missing teeth, filled teeth were 20 divided equally on the two arches, while total carious (decayed) teeth were 28 ; mainly affecting posterior teeth (Table 4 \& Fig. 5).

Table (4) Frequencies of missing $(M)$, carious $(D)$, and filled $(F)$ teeth counted from the included sample; presented as numbers and calculated as percentages (\%) according the total sample ( $n=28$ patient) and total number of teeth they should have $(28 \times 28=784$; wisdoms on the both dental arches were not included).

\begin{tabular}{|c|c|c|c|c|c|c|c|c|c|c|c|c|c|c|c|c|c|c|c|c|c|c|}
\hline \multirow{2}{*}{$\begin{array}{c}\text { Examination } \\
\text { Time }\end{array}$} & \multirow{2}{*}{$\begin{array}{c}\text { Upper } \\
\text { Anterior } \\
M F D\end{array}$} & \multirow{2}{*}{\multicolumn{3}{|c|}{$\begin{array}{c}\text { Upper } \\
\text { Posterior } \\
M F \quad D\end{array}$}} & \multicolumn{3}{|c|}{$\begin{array}{c}\text { Lower } \\
\text { Anterior }\end{array}$} & \multicolumn{3}{|c|}{$\begin{array}{c}\text { Lower } \\
\text { Posterior }\end{array}$} & \multicolumn{3}{|c|}{ Total Teeth } & \multicolumn{3}{|c|}{$\begin{array}{l}\text { Patients } \\
\text { No. with }\end{array}$} & \multicolumn{3}{|c|}{$\begin{array}{l}\text { Teeth } \\
\% \text { of }\end{array}$} & \multicolumn{3}{|c|}{$\begin{array}{c}\text { Patient \% } \\
\text { with }\end{array}$} \\
\hline & & & & & $M$ & $F$ & & $M$ & $F$ & & $M$ & $F$ & & $M$ & $F$ & $D$ & $M$ & $F$ & & $M$ & $F$ & $D$ \\
\hline $\begin{array}{c}\text { Before } \\
\text { Treatment }\end{array}$ & $\begin{array}{lll}0 & 0 & 0\end{array}$ & 8 & 7 & 0 & 0 & 0 & 0 & 8 & 9 & 0 & 16 & 16 & 0 & 4 & 4 & 0 & & 2 & 0 & 14 & 14 & 0 \\
\hline $\begin{array}{c}\text { After } \\
\text { Treatment }\end{array}$ & $\begin{array}{lll}0 & 0 & 8\end{array}$ & 8 & 10 & 9 & 0 & 0 & 4 & 8 & 10 & 7 & 16 & 20 & 28 & 4 & 6 & 5 & 2 & 3 & 8 & 14 & 21 & 18 \\
\hline
\end{tabular}

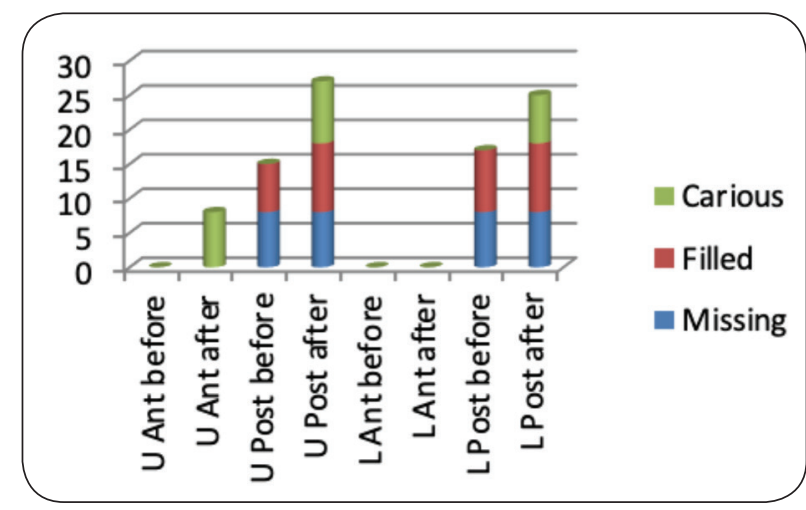

Fig. (5) Frequencies of missing / carious/ filled permanent teeth, recorded from the included sample, presented according to site in jaw as anterior (incisors \& canines) and posterior (premolars \& molars).

\section{DISCUSSION}

It has been acknowledged that orthodontic appliances create retentive areas for plaque accumulation and complicate oral hygiene, increasing risk for gingival inflammation, deteriorated periodontal health, dental demineralization and caries. ${ }^{18,}{ }^{20}$ Brackets bonding alter the ecology of the oral cavity, by the collection of biofilm at retentive areas; complexity of the orthodontic appliances represents difficulty to perform proper tooth cleaning by patients..$^{17,19}$ This study was carried out longitudinally on a group of
28 patients indicated to have orthodontic treatment. Their oral hygiene status was evaluated clinically and radiographically prior to treatment initiation as well as after treatment completion. During the performing of planned orthodontic treatment, oral hygiene of each patient was evaluated at $3^{\text {rd }}$ month as well as $9^{\text {th }}$ month to assess longitudinally the oral health status before, during as well as after their treatment with fixed orthodontic appliances. All of included patients completed the treatment, comply with various appointments and co-operated well in answering prepared questionnaire.

The results showed that all included patient were using tooth brushes to clean their mouth; regular tooth brushing is the first mean in the protocol of defense to control dental plaque. Majority of them $(60.7 \%)$ brush their teeth once a day, while $(29.3 \%)$ from the sample brushed twice a day (37.76\%), which is in accordance with previously reported. ${ }^{28-30}$ The patients of the present study were instructed to use Bass brushing method, as it has been showed that it is the most effective technique of tooth brushing because it eliminates plaque from the surface of the tooth and gingival surfaces $;{ }^{31}$ all included patients brushed their teeth 
using a conventional brush. In this respect, a study ${ }^{32}$ concluded that manual toothbrush was the first option of almost all participants and clean teeth sufficiently. It has been proposed that, the higher the frequency of tooth brushing, the lower the plaque biofilm accumulation, the obtained results from the present study lend support to this speculation. Thus, PI and GBI tend to decrease in patients with high reported frequency of regular tooth brushing process, however the difference did not reach a statistically significant level. Again, this finding was parallel to that of other studies ${ }^{29-33}$ found decreased gingival indexes mean scores as the patients clean their teeth more frequently and regularly. However, this was not always the case; conversely, a study ${ }^{34}$ reported that plaque accumulation in orthodontic patients was extremely high. This controversy can be attributed to several factors including sample size, state of orthodontic treatment, assessment method, patient's compliance with oral hygiene measures as well as frequency and efficacy of used cleaning aids; further clarification of this aspect is needed.

Results showed that majority of included patients mentioned that they used to brush their teeth daily (once / twice), which was the case reported in other studies. ${ }^{35-37}$ However, a study ${ }^{2}$ reported unsatisfactory oral hygiene in their patients even though more than half of them brushed twice daily and one-fifth 3 times daily. Tooth brushing procedure able to remove plaque under arch wires. ${ }^{38}$ Most of included patients $(71.4 \%)$ preferred soft bristles while $28.6 \%$ used medium tooth brush type; medium toothbrush removed more plaque but caused more gingival abrasion than soft toothbrush. ${ }^{35}$ The use of supplementary measures for oral hygiene as interdental toothbrush, dental floss, toothpaste containing fluoride (to avoid enamel demineralization), and oral irrigator has been advocated..$^{39,40}$ In the present study, it was found that $53.8 \%$ of included sample used interdental brush, $46.4 \%$ used mouthwash, while dental floss silk was used by $28.6 \%$ and toothpick used by only $21.4 \%$. It has been mentioned that use of interdental brushes eliminates subgingival plaque to a depth between 2 to $2.5 \mathrm{~mm} \cdot{ }^{37}$ Hence, more than halve of included sample were using brushing aids as interdental brushes; is higher percentage than that of a study ${ }^{35}$ found that $18 \%$ of subjects use interdental brushes regularly, but another study reported that $68,6 \%$ of patients treating by fixed orthodontic appliances used interdental toothbrushes daily. ${ }^{36}$ In addition, $55 \%$ of patients included in the present study reported the use of mouthwash to aid in oral cleansing process. These oral hygiene aids (toothbrush, dental floss, interdental cleanser, chewing gum) as well as antibacterial agents (mouth rinses, dentifrices, chewing gum) are valuable mechanical oral cleansing methods.

Periodontal clinical evaluation was assessed with PI, GI, PPD showed that orthodontic appliances were associated with development of more plaque accumulation with clinical signs of orthodontic gingivitis within few months. Such gingival changes associated with orthodontic therapy have been reported in various studies, ${ }^{41,42}$ however, Liu et al. reported that there are transient changes; no permanent effects on gingival status occurred from orthodontic appliances use. ${ }^{20}$ Additionally, results of present study showed that after 3 months from treatment termination, the gingiva returned to normal condition without inflammatory changes. This finding was in accordance with a study, ${ }^{43}$ reported that periodontal values tended to normalize 3 months after fixed appliance removal even if the same parameters remained higher with respect to baseline. In this respect a study concluded that, fixed appliance placement does not have a long-term impact on clinical periodontal parameters; in fact, many values normalized 2 years after de-bonding. ${ }^{44}$ Other research conducted on a wider sample size with includes a control group and a longer follow up period to obtain clear understanding and clarification regarding influence of fixed appliances on periodontal health, are needed. 


\section{ACKNOWLEDGEMENT:}

The authors express their grateful to Prof.AbdelFattah Amer (BDS, MSc, Ph.D., Wales University, $U K)$, for his valuable guidance, advices and revision of the manuscript; in fact the role played by him during preparation as well performing this study cannot be forgotten.

\section{REFERENCES}

1. Karkhanechi M, Chow D, Sipkin J, Sherman D, Boylan R, Norman R, et al: Periodontal status of adult patients treated with fixed buccal appliances and removable aligners over one year of active orthodontic therapy. Angle Ortho. 2013, $1 ; 83(1): 146-51$.

2. Atassi F,Awartani F: Oral hygiene status among orthodontic patients. J Contemp Dent Pract, 2010, 11: E025-032

3. Al-harbi A, Alkhulayfi A, Alharbi A, Al-harbi A, Al-harbi $\mathrm{N}$ : Knowledge of patients about association between orthodontic treatment and periodontal diseases. Int J Oral Care Res. 2018; 6(2):43-6.

4. Bollen A, Cunha-Cruz J, Bakko D, Huang G, Hujoe 1: The effects of orthodontic therapy on periodontal health. A systematic review of controlled evidence. J A D A, 2008, 139: 413-22.

5. Guo R; Lin,Y; Zheng Y; Li W: The microbial changes in subgingival plaques of orthodontic patients: A systematic review and meta-analysis of clinical trials. BMC Oral Heal. 2017, 17, 1-10.

6. Lemos M; Cattaneo P; Melsen B; Faveri M; Feres M; Figueiredo C: Impact of Treatment with Full-fixed OrthodonticAppliances on the Periodontium and the Composition of the Subgingival Microbiota. J Int Acad Periodontol. 2020, 22, 174-81.

7. Elkordy S, Palomo L, Palomo J, Mostafa Y: Do fixed orthodontic appliances adversely affect the periodontium? A systematic review of systematic reviews. Semin Orthod, 2019, 25(2):130-57.

8. Hadler-Olsen S, Sandvik K, El-Agroudi M, Ogaard $\mathrm{B}$ : The incidence of caries and white spot lesions in orthodontically treated adolescents with a comprehensive caries prophylactic regimen- a prospective study. Eur J Orthod; 2012, 34: 633-9.
9. Kim S; Choi D; Jang I.; Cha B; Jost-Brinkmann P; Song $\mathrm{J}$ : Microbiologic changes in subgingival plaque before and during the early period of orthodontic treatment. Angle Orthod. 2012, 82, 254-60.

10. Pan S; Liu Y; Si Y; Zhang Q; Wang L; Liu J; Wang C; Xiao S: Prevalence of fimA genotypes of Porphyromonas gingivalis in adolescent orthodontic patients. PLoS ONE 2017, 12, e0188420.

11. Lucchese, A.; Bondemark, L.; Marcolina, M.; Manuelli, M. Changes in oral microbiota due to orthodontic appliances: A systematic review. J. Oral Microbiol. 2018, 10, 1476645.

12. Papageorgiou S, Xavier G, Cobourne M, Eliades T: Effect of orthodontic treatment on the subgingival microbiota: A systematic review and meta-analysis. Orthod Craniofac Res. 2018; 21(4):175-85.

13. Naranjo A; Triviño M; Jaramillo A; Betancourth M; Botero $\mathrm{J}$ : Changes in the subgingival microbiota and periodontal parameters before and 3 months after bracket placement. Am. J. Orthod. Dentofac. Orthop. 2006, 130, 275-e17.

14. Sun F; Ahmed A; Wang L; Dong M; Niu W: Comparison of oral microbiota in orthodontic patients and healthy individuals. Microb. Pathog. 2018, 123, 473-7.

15. Lo B; Di Marco R; Milazzo I; Nicolosi D; Calì G; Rossetti B; Blandino G: Microbiological and clinical periodontal effects of fixed orthodontic appliances in pediatric patients . N Micro 2008, 31: 299.

16. Anhoury P; Nathanson D; Hughes C; Socransky S; Feres M; Chou L: Microbial profile on metallic and ceramic bracket materials. Angle Orthod. 2002, 72, 338-43.

17. Klaus K; Eichenauer J; Sprenger R; Ruf S: Oral microbiota carriage in patients with multi-bracket appliance in relation to the quality of oral hygiene. Head Face Med. 2016, 12, 1-7.

18. Müller K; Jungbauer G; Jungbauer R; Wolf M; Deschne, $\mathrm{J}$ : Biofilm and Orthodontic Therapy. Monographs in Oral Sci 2021, 29, 201-13.

19. Gorelick L, Geiger A, Gwinnett A: Incidence of white spot formation after bonding and banding. Am J Orthod, 1982,81: 93-8.

20. Liu H, Sun J, Dong Y, et al. Periodontal health and relative quantity of subgingival Porphyromonas gingivalis during orthodontic treatment. Angle Orthod 2011; 81(4): 609-15

21. van Gastel J, Quirynen M, Teughels W, Carels C. Longitudinal changes in microbiology and clinical periodontal parameters after removal of fixed orthodontic appliances. Eur J Orthod 2011; 33: 15-21. 
22. Thornberg M, Riolo C, Bayirli B, Riolo M, Van Tubergen E, Kulbersh R: Periodontal pathogen levels in adolescents before, during, and after fixed orthodontic appliance therapy. Am J Orthod Dentofacial Orthop 2009; 135(1): 95-8.

23. Ghijselings E, Coucke W, Verdonck A: Long-term changes in microbiology and clinical periodontal variables after completion of fixed orthodontic appliances. Orthod Craniofac Res 2014; 17(1): 49-59.

24. Silness J, Loe H. Periodontal disease in pregnancy. II. Correlation between oral hygiene and periodontal condition. Acta Odontol Scand 1964; 22:121e35

25. Löe H, Silness J. Periodontal Disease in Pregnancy I. Prevalence and Severity. Acta Odontol Scand. 1963; 21(6):533-51

26. World Health Organization: Oral Health Surveys. Basic Methods. Geneva: World Health Organization, 1997

27. World Health Organization: Oral health surveys basic method (4th ed) Geneva, WHO 1987: 760.

28. Petrauskiene S, Wanczewska N, Slabsinskiene E, Zemgulyte G. Self-Reported Changes in Oral Hygiene Habits among Adolescents Receiving Orthodontic Treatment. Dent J. 2019 Oct 1;7(4):96.

29. Wang S, Yang Y, Chang H: The effect of an oral hygiene intervention on plaque control by orthodontic patients. J Dent Sci, 2007; 2: 45-51.

30. Cerroni S, Pasquantonio G, Condò R, Cerroni L: Orthodontic Fixed Appliance and Periodontal Status: An Updated Systematic Review. Open Dent J. 2018, 28;12(1):614-22.

31. Zimmer S, Öztürk M, Barthel C, Bizhang M, Jordan R: Cleaning efficacy and soft tissue trauma after use of manual toothbrushes with different bristle stiffness. J Periodontol, 2011; 82: 267-71.

32. Zanatta F, Bergoli A, Werle S, Antoniazzi R: Biofilm removal and gingival abrasion with medium and soft toothbrushes. Oral Health Prev Dent, 2011; 9: 177-83.

33. Kawsar M, Islam M, Rezwana R, Prodhan M, Habib M, Abdullah M: Gingival Bleeding Index Status Among Orthodontic Patients Treated with Fixed Orthodontic Appliances in a Tertiary Level Hospital. KYAMC J. 2018,4;9(3):129-32.
34. Klukowskaa M, Baderb A, Erbec C, Bellamyd P, Donald J, Mary W, et al: Plaque levels of patients with fixed orthodontic appliances measured by digital plaque image analysis. Am J Orthodont Dendtofaci Orthopedics 2011; 139 (5):e463 -70.

35. Arici S, Alkan A, Arici N: Comparison of different tooth brushing protocols in poor-toothbrushing orthodontic patients. Eur J Orthod, 2007; 29: 488- 92.

36. Yener S, Özsoy Ö: Quantitative analysis of biofilm formation on labial and lingual bracket surfaces. Angle Orthod. 2020, 1;90(1):100-8.

37. Mei L, Chieng J, Wong C, Benic G, Farella M: Factors affecting dental biofilm in patients wearing fixed orthodontic appliances. Prog Orthod. 2017;18(1):4.

38. Huang J, Yao Y, Jiang J, Li C: Effects of motivational methods on oral hygiene of orthodontic patients: A systematic review and meta-analysis. Medicine (Baltimore), 2018; 97(47):e13182.

39. Zanatta F, Moreira C, Rösing C: Association between dental floss use and gingival conditions in orthodontic patients. Am J Orthod Dentofacial Orthop. 2011; 140(6):812-21.

40. Lee J, Abdullah A, Yahya N: Oral Hygiene Practices among Fixed Orthodontic Patients in a University Dental Setting. Int J Oral Dent Health. 2016;2(2).

41. Verrusio C, Iorio-Siciliano V, Blasi A, Leuci S, Adamo $\mathrm{D}$, Nicolò $\mathrm{M}$. The effect of orthodontic treatment on periodontal tissue inflammation: A systematic review. Quintessence Int. 2018; 49:69-77.

42. Giugliano D; D’Apuzzo F; Majorana A; Campus G; Nucci F; Flores-Mir C; Perillo L: Influence of occlusal characteristics, food intake and oral hygiene habits on dental caries in adolescents: A cross-sectional study. E J Paedia Dent 2018, 19, 95-100.

43. van Gastel J, Quirynen M, Coucke W, Carels C: Longitudinal changes in microbiology and clinical periodontal variables after placement of fixed orthodontic appliances. J Periodontol 2008; 79: 2078-86.

44. Brusca M, Chara O, Sterin-Borda L, Rosa A: Influence of different orthodontic brackets on adherence of microorganisms in vitro. Angle Orthod, 77: 331-336, 2007 
مجلة أسيوط لطب الأسنان
النشر الرسمي لكلية طب الأسنان جامعة الأزهر أسيوط الكاية

مصر جامعة

\section{تقييم طولي لصحة الفم لدمي مرضي العلاج التقويمي للأسنان: قبل وأثناء وبعد الانتهاء مرضه العنه}

\section{هشام محمد أبو زيد 1*3، ليلي عبدالفتاح عامر2}

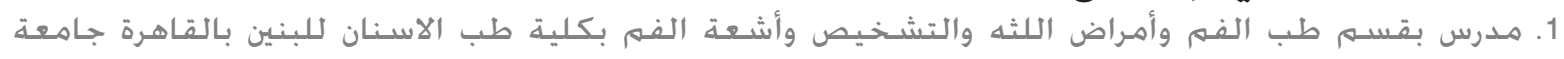

الازهر

2. مدرس تقويم الاسنان بكلية طب الفهم والاسنان بالجامعة الحديثة

* "HISHAMABOUZAID.209@AZHAR.EDU.EG *

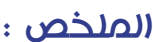

الهدف: التقييم الاكلينيكي للحالة الصحية للفم عند المعالجون بتقويم الاسنان بمتابعتهم قبل البدء بالعلاج وأثناء العلاج وبعد ثلاثة شهور من انتهاء العلاج التقويمي للاسـنان.

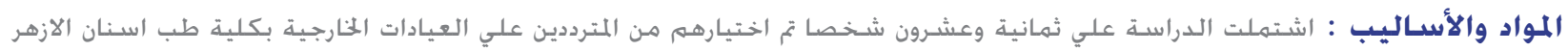

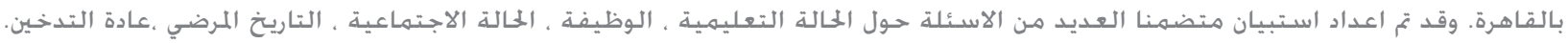

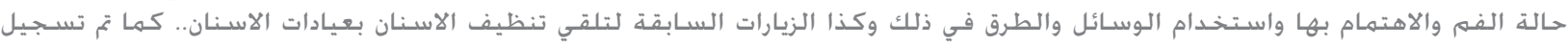

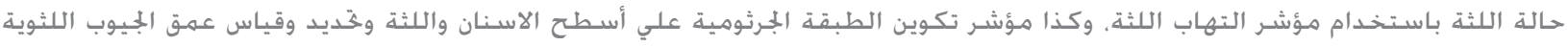

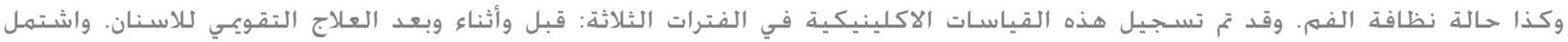

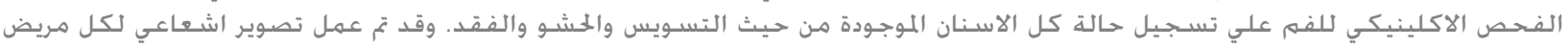
قبل وبعد العلاج التقويمي.

النتائج: وقد أظهرت النتائج ان أكثر من نصف المرضي طلابا، و25 \% يعملون والنسبة الباقية بدون عمل. وأن الغالبية العظمي غير مدخنين...

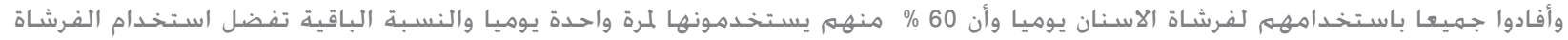

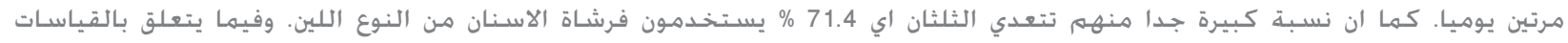

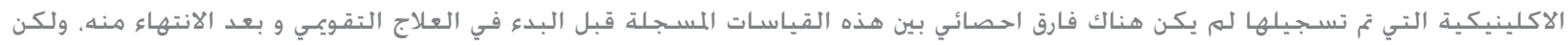

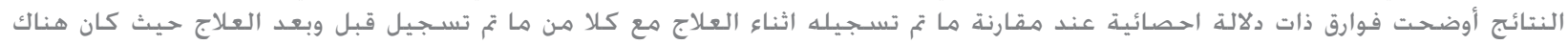

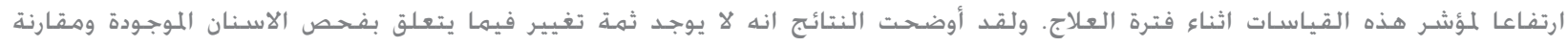

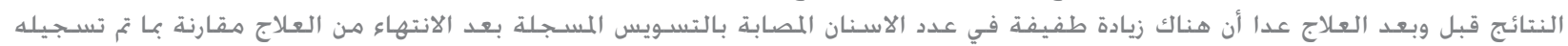
قبل البدء بالتقويم ولكن الفارق لم يصل للأهمية الاحصائية.

المخلاصة: زيادة تراكم الطبقة الجرثومية علي الاسنان واللثة يؤدي الي تغييرات مرضية كنتيجة لصعوبة تنظيف الفم مع وجود أجهزة التقويم

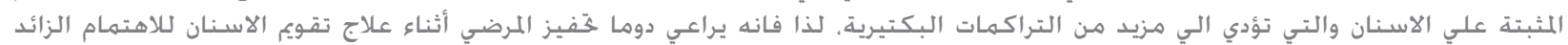
بحالة الفم والتنظيف المستمر والمنتظم للفم والاسنان لتجنب حدوث التهابات اللثة أو تسـويس الاسنان. الكلمات المفتاحية: مؤشر التهاب اللثه، مرضى تقويم الاسنان , صحة الفم ، التهاب اللثه، التراكمات البكتيريه 